\title{
The Count Me In! Program: An Innovative Approach to Supporting Community Participation for Seniors Living with Psychosocial Difficulties
}

\author{
Ginette Aubin \\ Université du Québec à Trois-Rivières \\ Manon Parisien \\ Institut universitaire sur la réadaptation en déficience physique de Montréal (IURDPM) \\ Norma Gilbert \\ Integrated Health and Social Services University Network for West-Central Montreal \\ Bernadette Dallaire \\ Laval University \\ Véronique Billette \\ Research Team in Partnership Vieillissements, exclusions sociales et solidarités (VIES) \\ Julie Beauchamp \\ Integrated Health and Social Services University Network for West-Central Montreal
}

\begin{abstract}
Ginette Aubin, Centre for Research and Expertise in Social Gerontology (CREGES) of the Integrated Health and Social Services University Network for South-Central Montreal, Université du Québec à Trois-Rivières, Trois-Rivières, QE; Manon Parisien, Institut universitaire sur la réadaptation en déficience physique de Montréal (IURDPM), CIUSSS du Centre-Sud-de-l'Île-de-Montréal, Montréal, QE; Norma Gilbert, Centre for Research and Expertise in Social Gerontology (CREGES) of the Integrated Health and Social Services University Network for West-Central Montreal, Montréal, QE; Bernadette Dallaire, Institute on Ageing and Social Participation of the Elderly, Laval University, Quebec City, QE; Véronique Billette, Research Team in Partnership Vieillissements, exclusions sociales et solidarités (VIES), National Institute of Scientific Research (INRS), Montreal, QE; Julie Beauchamp, Centre for Research and Expertise in Social Gerontology (CREGES) of the Integrated Health and Social Services University Network for West-Central Montreal, Montréal, QE.

Funding for the development of the program was received from the Health and Social Services Ministry of Québec (MSSS) and the Research Funds - Society and Culture (FRQSC) to support the university affiliation designation (CAU) in social gerontology of the CIUSSS West-Central Montreal. A grant from the Quebec Network for Research on Aging (RQRV) was received for the study and testing of the program. The VIES team, funded by the FQRSC, also contributed to the financing of the project. The program also benefited from the support of the Bell Let's Talk Community Fund (2016) for the video production and the distribution of the program across Canada.
\end{abstract}




\begin{abstract}
To better support the social participation of seniors with mental health or psychosocial challenges, we developed a manualized group program. Following program testing, participating agencies and group leaders expressed their appreciation of the program and identified its facilitators and barriers. The revised version is available in French and English.
\end{abstract}

Keywords: social participation, older adults, psychosocial issues, community, intervention

\title{
RÉSUMÉ
}

Afin de mieux soutenir la participation sociale des aînés aux prises avec des problèmes de santé mentale ou des difficultés d'ordre psychosocial, un programme de groupe a été développé. À la suite de la mise à l'essai du programme, les responsables des organismes participants et les animateurs ont manifesté leur appréciation et ont identifié les facilitateurs et les obstacles afférents. La version révisée du programme est disponible en français et en anglais.

Mots clés : participation sociale, aînés, problématiques psychosociales, communauté, intervention

Factors leading to social exclusion such as the presence of a mental health challenge or psychosocial difficulties can have a cumulative effect for older adults (seniors) already at risk of age-related social isolation (Nour, Dallaire, Regenstreif, Hebert, \& Moscovitz, 2010). It is well known that between 20\% and 25\% of older adults live with a mental health problem (Bartels, 2004, cited in Nour et al., 2010). However, social participation has been found to have a positive effect on the well-being and quality of life of older adults (Levasseur, Desrosiers, \& St-Cyr Tribble, 2008). Currently in Quebec, few services or resources are adapted to support the social participation of seniors living with psychosocial or mental health challenges (MHC; Trépanier, 2011). Consequently, the development of interventions promoting community participation for these seniors is essential.

With this in mind, members and collaborators from the Centre for Research and Expertise in Social Gerontology (CREGÉS) in partnership with the Research Team Vieillissements, exclusions sociales et solidarités (VIES) developed the Count Me In! program (otherwise known as Participe-présent in its French version; Parisien et al., 2018). The aim of this program is to promote the community participation of seniors with MHC (e.g., depression, anxiety, bipolar disorder) or psychosocial problems (e.g., bereavement, social isolation) that leads to an alteration in their social participation (Parisien et al., 2017). Reactions to the Count Me In! program's French version during its recent pilot testing in Quebec, including appreciation, facilitators, constraints and challenges are briefly summarized in this article.

Correspondence concerning this article should be addressed to Ginette Aubin, Département d'ergothérapie, Université du Québec à Trois-Rivières, 3351, boul. des forges, C.P. 500, Trois-Rivières, Québec G9A 5H7. Email: ginette.aubin@uqtr.ca 


\section{THE COUNT ME IN! PROGRAM}

Count Me In! is a "ready-to-use" program that can be offered by community organizations, residential resources or institutions from the health and social services network. The four components of the program are based on a logic model, which applies a strength-based approach and adopts health education and motivational strategies (Parisien et al., 2018). It consists of:

1. A one-on-one interview to be held at the beginning of the program, during which the participants are encouraged to identify a personal goal related to community participation and use of community services and resources for activities. Opportunities for social interaction are also sought through these activities.

2. Psychoeducational group workshops of eight sessions addressing various themes (see Table 1 below). These sessions are viewed as the core element of the program, supporting and linking the other program components. It should be noted that themes were selected following a literature review and consultation with stakeholders and representatives of the target population. These workshops are designed to build and support the participants' skills relative to their community participation. They are highly adaptable, offering a variety of activities (e.g., role playing, discussions, reflections) from which the group leader can choose those most relevant for the members of the group. Workshop tools are offered for each of the sessions.

Table 1

Themes of the Count Me In! Program Workshop

$\begin{array}{ll}\text { Session } 1 & \text { What does participation involve? } \\ \text { Session } 2 & \text { Targeting your strengths } \\ \text { Session } 3 & \text { The community: A source of opportunities } \\ \text { Session } 4 & \text { Aging: How to adapt? } \\ \text { Session } 5 & \text { Spending to participate? } \\ \text { Session } 6 & \text { Communication: A tool for participating } \\ \text { Session } 7 & \text { Social networks: Staying connected } \\ \text { Session } 8 & \text { Community networks: Finding your voice }\end{array}$

3. Visits to community resources are organized with the participants of the workshop. Inter-organizational collaboration is sought to promote social participation as well as increase the awareness of community organizations regarding the needs of the elderly. As the goal is to promote participation in the resources, community organizations can also send someone to meet with the participants when needed.

4. During the workshops, collaborative media capsules inspired by the themes of community participation, mental health and aging are created, with the goal of raising awareness of the citizens and members of the organizations offering the program. With that objective in mind, participants choose from group discussions, reflections, and anecdotes they wish to express via a previously chosen 
media (e.g., artistic medium, website of the organization, bulletin board, or internal newspaper) in the larger perspective of health determinants (acting on prejudice, stigma, and discrimination).

The manual also includes a section for the leaders on seniors' group facilitation, suggestions for elements to be taken into consideration, and steps to take in the preparation of the workshops. This program is particularly relevant when seen in a perspective of empowerment and combating social exclusion. The participants ultimately become agents in the community and are present in a space they are not used to occupying.

\section{Appreciation of the Count Me In! Program by Participating Agencies and Group Leaders}

Five organizations have applied the program in Quebec, three of which were community organizations offering various activities (e.g., recreation, education, support) to people with mental health challenges. In addition, a day centre for people with mobility problems implemented the program as well as an organization that provides support and assistance to seniors living in low-rent social housing. Count Me In! senior participants $(n=42)$ mentioned that they very much appreciated being together with other seniors, helping each other, and finding the motivation to do something different. The group leaders $(n=5)$ and participating agency leaders $(n=4)$ also expressed their appreciation of the program. Positive feedback was provided regarding the program's strong theoretical foundations, its innovative approach, and focus on empowerment.

The group leaders indicated that the program is relevant and responsive to the participants' needs, the material is adaptable, the workshop tools are simple to use, and the didactic aspects of the program (e.g., meeting plans) make the implementation of the program easier. The constraints identified were mainly related to the abundant amount of material offered by the program, the amount of organization required for the planning of the workshops and the application of the program in specific contexts. For example, some participants had difficulties retaining the information or maintaining their engagement in the group. Challenges in adaptation were mentioned, for example, one of the group leaders needed to quickly adapt the activities with written content for an illiterate person.

\section{CONCLUSION}

It appears that the Count Me In! program was well appreciated by the seniors and given its adaptability, seems to be applicable for people with different psychosocial issues. This intervention has the potential to respond to the needs of seniors living with MHC or psychosocial difficulties related to their community participation, while helping to deconstruct prejudices against them. To our knowledge, this inclusive vision for this population is unique to this program. More research is needed on the effect of this program on community participation in the long term.

Following the comments from the participating agencies and group leaders, the program has been revised (see Parisien et al., 2017). The challenges that were identified suggest some aspects may require the investment of more time by the group leaders to tailor the program to the participants' needs. However, the interest and the satisfaction shown by the group and agency leaders are promising and encourage us to further implement and evaluate the Count Me In! program. 
The research team is pursuing the evaluation of the revised version of the program with the objective of producing an implementation guide. The Group Leader's manual is available in both French and English and can be downloaded free of charge on the CREGES website (https://www.creges.ca/programs-guidesand-tools/?lang=en). A study of the implementation of the program in English-speaking organizations is now also under consideration for communities outside Quebec.

\section{REFERENCES}

Levasseur, M., Desrosiers, J., \& St-Cyr Tribble, D. (2008). Do quality of life, participation and environment of older adults differ according to level of activity? Health and Quality of Life Outcomes, 6(1), 30.

Nour, K., Dallaire, B., Regenstreif, A., Hébert, M., \& Moscovitz, N. (2010). Santé mentale et vieillissement. Problèmes, répercussions et services. In M. Charpentier, N. Guberman, V. Billette, J.-P. Lavoie, A. Grenier, \& I. Olazabal (Eds.), Vieillir au pluriel. Perspectives sociales (pp. 135-160). Québec: Presses de l'Université du Québec.

Parisien, M., Nour, K., Belley, A. M., Aubin, G., Billette, V., \& Dallaire, B. (2017). Participe-présent : co-construction d'un programme visant la participation communautaire des aînés qui vivent des difficultés psychosociales. Santé Mentale au Québec, 42(1), 183-204. doi:10.7202/1040250ar

Parisien, M., Nour, K., Belley, A. M., Billette, V., Aubin, G. \& Regenstreif, A. (2018). Participe-Présent. Promouvoir la participation communautaire et la santé mentale des aînés. Guide d'animation, Centre affilié universitaire (CAU) en gérontologie sociale du CIUSSS du Centre-Ouest-de-l'Île-de-Montréal et Équipe de recherche en partenariat Vieillissements, exclusions sociales et solidarités (VIES). https://www.creges.ca/programmes-guides-et-outils/

Trépanier, J. (2011). Santé mentale et vieillissement. Recueil de réflexions et de pratiques observées en matière de services à offrir aux personnes âgées présentant une problématique de santé mentale. Document d'information, Plan de mise en oeuvre à Montréal - Phase III. Retrieved from http://publications.santemontreal.qc.ca/uploads/ tx_asssmpublications/isbn978-2-89510-796-5.pdf 